\author{
Wladyslaw Koc \\ prof. dr hab. inż. \\ Politechnika Gdańska \\ Katedra Transportu Szynowego i Mostów \\ kocwl@pg.gda.pl

\section{Katarzyna Palikowska} \\ dr inż. \\ Politechnika Gdańska \\ Katedra Transportu Szynowego i Mostów \\ katpalik@pg.gda.pl
}

DOI: 10.35117/A_ENG_17_10_01

\title{
Determination of the optimal curvature of the turnout diverging track for HSR using dynamic analysis
}

\begin{abstract}
The paper presents an analytical method of identifying the curvature of the turnout diverging track consisting of sections of varying curvature. Such turnout is mainly applied on High Speed Railway. Both linear and nonlinear (polynomial) curvatures of the turnout diverging track are considered in the paper. Obtained solutions enable to assume curvature values at the beginning and end point of the geometrical layout of the turnout.The paper focus on a fundamental and unexplained so far issue connected with selection of the most favourable curvature section from the operational requirements point of view. In order to determine the optimal curvature a dynamic analysis has been carried out on the several representative cases. It has been indicated that, used in railway practice, clothoid sections with nonzero curvatures at the beginning and end points of the turnout should be verified. It has been proved that the turnout with nonlinear curvature reaching zero values at the extreme points of the geometrical layout is the most favourable.
\end{abstract}

Keywords: Railway turnouts; Curvature modelling; Dynamics analysis

\section{Introduction}

In a typical applied geometrical layout of the turnout diverging track, a single circular arc is used without transients. This solution means tolerating the places of rapid, abrupt change in the ordinates of the curvature diagram at the beginning and the end of the geometric system in question, which results in the rapid appearance of significant dynamic interactions. This makes it necessary to limit the speed of trains on turnouts and is particularly disadvantageous on high-speed railways. Therefore, it is necessary to look for new geometrical solutions that will eliminate this problem.

In recent years, in some countries, especially on high-speed railways, the aim is to alleviate the curvature diagram in sensitive regions. For this purpose, there are so-called "sections of clothoid" on both sides of a circular arc, on which the curvature varies in a linear manner, but often without reaching zero values in the endpoints $[9,10,11]$. In the turnout with segments of the linear curvature, the length of the return track is divided into three zones (Fig. 1):

- initial zone with length $l_{1}$, with a linearly rising curvature,

- middle zone with length $l_{2}$, with a fixed curvature,

- end zone with length $l_{3}$, with a linearly decreasing curvature. 


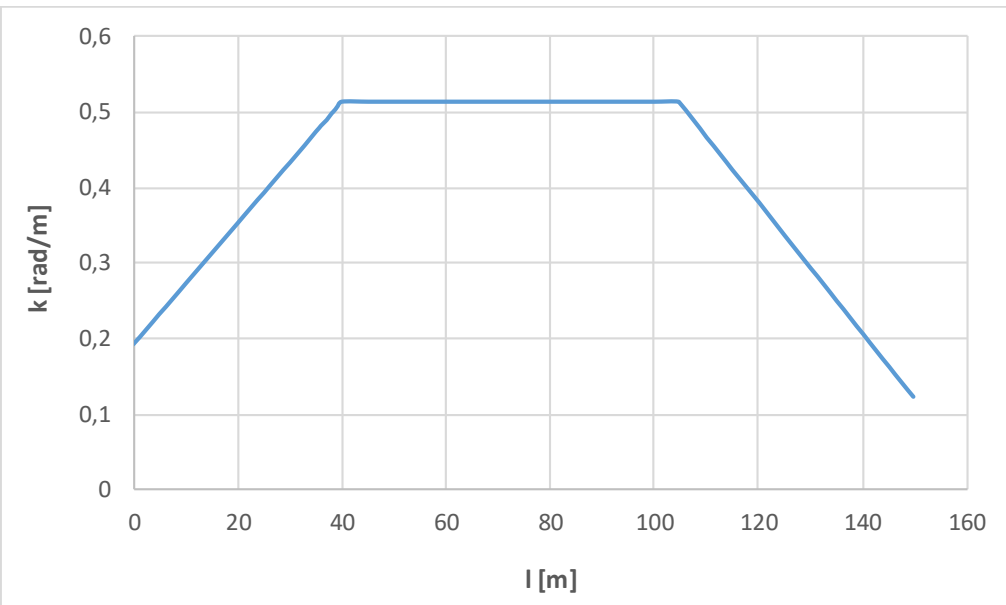

1. Diagram of curvature with linear sections along the turnout diverging track $\left(R_{1}=16000 \mathrm{~m}, l_{1}=40 \mathrm{~m}, R_{2}=6000 \mathrm{~m}, l_{2}=64,584 \mathrm{~m}, l_{3}=45 \mathrm{~m}, R_{3}=25000 \mathrm{~m}\right)$

Of course, different variants are possible here, related to the curvature values and lengths of individual zones. In addition, the curvature curve shown in Figure 1 is not an ideal solution. It would be worth to consider the possibility of mitigating (i.e. the elimination of the kinks on the curvature diagram) of the regions of entry into the circular arch of the turnout.

As you can see, each turnout diverging track with segments of the variable curvature is described by means of 6 parameters. Even if we take into account the limiting conditions resulting from the slant travel angle and the final elevation value, the number of possible variants turns out to be very large. In paper [5] an attempt was made to pre-evaluate selected geometrical cases using dynamic analysis. Now it was decided to approach the problem in a methodical way and determine the most advantageous from the point of view of dynamics of the curvature of the diverging track in the railway turnout.

The modeling of curvature along the turnout diverging track allows creating its analytic record in the form of a $k(l)$ function, where the parameter $l$ determines the position of a given point along the curve's length. In this work, appropriate analytical equations have been determined for both cases of already used linear curvature segments as well as for the proposed non-linear sections (in polynomial form). This made it possible to conduct a dynamic analysis of selected variants and on its basis to indicate the most advantageous geometric solution.

\section{The use of linear curve segments}

In the initial zone of the turnout diverging track, the $k(l)$ curvature describes the equation [3]

$$
k(l)=k_{1}+\frac{k_{2}-k_{1}}{l_{1}} l
$$

In the circular arc zone, i.e. for $l \in\left\langle l_{1}, l_{1}+l_{2}\right\rangle$, there is a constant $k(l)=k_{2}$ curvature. In the final zone of the turnout the equation of curvature is as follows :

$$
k(l)=k_{2}-\frac{k_{3}-k_{2}}{l_{3}}\left(l_{1}+l_{2}\right)+\frac{k_{3}-k_{2}}{l_{3}} l
$$

The value of the tangent angle at the end of the turnout is

$$
\theta\left(l_{1}+l_{2}+l_{3}\right)=\frac{k_{1}+k_{2}}{2} l_{1}+k_{2} l_{2}+\frac{k_{2}+k_{3}}{2} l_{3}
$$

On this basis, we can determine the slant of the turnout $\frac{1}{n}$. The value $n$ amounts 


$$
n=\frac{1}{\tan \theta\left(l_{1}+l_{2}+l_{3}\right)}
$$

\section{Application of nonlinear curvature}

In the initial zone of the turnout diverging track after entering $C \geq 0$ a numerical coefficient, we obtain

$$
k(l)=k_{1}+\frac{C}{l_{1}}\left(k_{2}-k_{1}\right) l-\frac{2 C-3}{l_{1}^{2}}\left(k_{2}-k_{1}\right) l^{2}+\frac{C-2}{l_{1}^{3}}\left(k_{2}-k_{1}\right) l^{3} .
$$

Obtaining a correct solution requires adopting the appropriate $C$ parameter value. The function of $k(l)$ curvature in the considered zone must be a monotonic function, increasing for $l>0$. As it has been shown, parameter $C$ must take values from the range $C \in\langle 1,5 ; 3\rangle$. Due to the ratio of the length of the parametric curve to the length of the curve with linear curvature (i.e. generalized clothoid), the most preferred solution seems to be the parametric $C=1,5$ transitional curve. The $k(l)$ function accepts a character for it:

$$
k(l)=k_{1}+\frac{3}{2 l_{1}}\left(k_{2}-k_{1}\right) l-\frac{1}{2 l_{1}^{3}}\left(k_{2}-k_{1}\right) l^{3}
$$

As with the use of linear curvature segments, a constant curvature exists in the circular arc zone, i.e. for $l \in\left\langle l_{1}, l_{1}+l_{2}\right\rangle$, there is a constant curvature. $k(l)=k_{2}$. In the end zone of the turnout (for $C=1,5$ ) the equation of curvature is as follows:

$$
k(l)=c_{1}+c_{2} l+c_{3} l^{2}+c_{4} l^{3}
$$

where

$$
\begin{aligned}
& c_{1}=k_{2}+\left[\frac{3}{2 l_{3}^{2}}\left(l_{1}+l_{2}\right)^{2}+\frac{1}{2 l_{3}^{3}}\left(l_{1}+l_{2}\right)^{3}\right]\left(k_{3}-k_{2}\right) \\
& c_{2}=-\left[\frac{3}{l_{3}^{2}}\left(l_{1}+l_{2}\right)+\frac{3}{2 l_{3}^{3}}\left(l_{1}+l_{2}\right)^{2}\right]\left(k_{3}-k_{2}\right) \\
& c_{3}=\left[\frac{3}{2 l_{3}^{2}}+\frac{3}{2 l_{3}^{3}}\left(l_{1}+l_{2}\right)\right]\left(k_{3}-k_{2}\right) \\
& c_{4}=-\frac{1}{2 l_{3}^{3}}\left(k_{3}-k_{2}\right)
\end{aligned}
$$

The angle of tangent at the end of the turnout for $l=l_{1}+l_{2}+l_{3}$ is described by the following formula:

$$
\theta\left(l_{1}+l_{2}+l_{3}\right)=\frac{3 k_{1}+5 k_{2}}{8} l_{1}+k_{2} l_{2}+\frac{3 k_{3}+5 k_{2}}{8} l_{3}
$$

Figure 2 shows a $k(l)$ curvature diagram for $C=1,5$ the length of the turnout diverging track with non-linear curves and numerical characteristics corresponding to the example of the switch shown in the figure $\mathbf{1}$. 


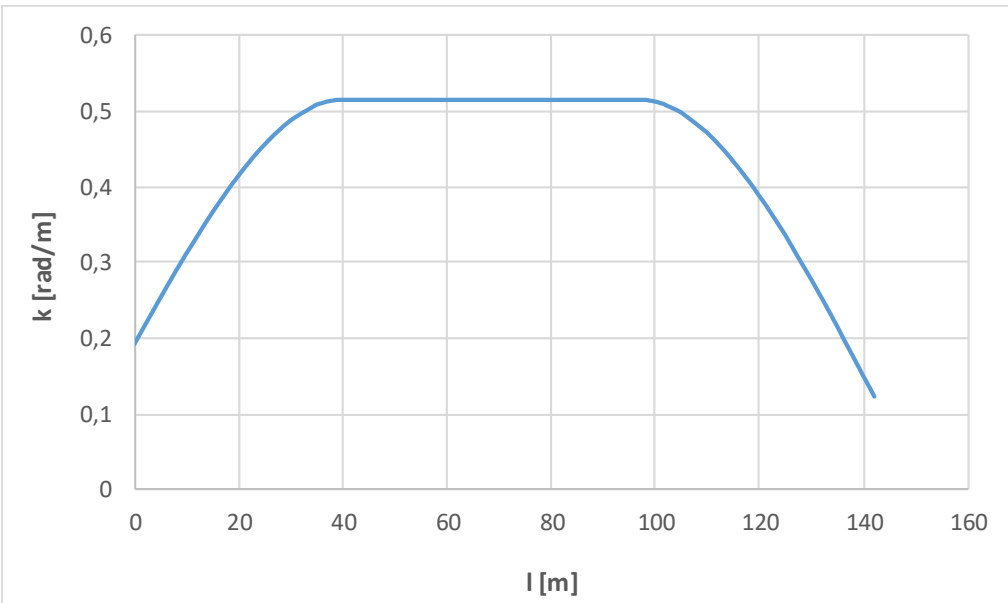

2. Diagram of curvature with nonlinear sections for $C=1,5$ the length of turnout diverging $\operatorname{track}\left(R_{1}=16000 \mathrm{~m}, l_{1}=40 \mathrm{~m}, R_{2}=6000 \mathrm{~m}, l_{2}=57,184 \mathrm{~m}, l_{3}=45 \mathrm{~m}, R_{3}=25000 \mathrm{~m}\right)$

\section{Selection of variants for dynamic analysis}

The purpose of the dynamic analysis was to compare the transverse accelerations occurring at selected turnouts. To ensure the reliability of such analysis, the following assumptions were made:

- the same turnout slant applies $1: n$, with $n=50$,

- the values of the $k_{2}$ constant curvature are the same in the compared cases,

- values of the $k_{1}$ and $k_{3}$ variable curvature are equal, but in the compared cases they change and amount $0,75 k_{2}, 0,5 k_{2}, 0,25 k_{2}$ i 0 ,

- the length of the $l_{1}$ initial zone and the $l_{3}$ end zone are equal to each other (provided that the appropriate kinematic conditions are met),

- the length of the $l_{2}$ circular arc closes the given geometrical system, ensuring the achievement of the set gradient of the turnout. 
Tab 1. List of geometrical parameters for selected turnouts with slant 1:50.

\begin{tabular}{|c|c|c|c|c|c|c|c|c|}
\hline & Curvature & $\begin{array}{l}k_{1} \\
{[\mathrm{rad} / \mathrm{m}]}\end{array}$ & $l_{1}[\mathrm{~m}]$ & $\begin{array}{l}k_{2} \\
{[\mathrm{rad} / \mathrm{m}]}\end{array}$ & $l_{2}[\mathrm{~m}]$ & $\begin{array}{l}l_{3} \\
{[\mathrm{~m}]}\end{array}$ & $\begin{array}{l}k_{3} \\
{[\mathrm{rad} / \mathrm{m}]}\end{array}$ & {$[\mathrm{m}]$} \\
\hline 1 & constant & 0 & 0 & $1 / 6000$ & 119,984 & 0 & 0 & $\begin{array}{c}119,98 \\
4\end{array}$ \\
\hline 2 & & $1 / 8000$ & 15 & $1 / 6000$ & 93,734 & 15 & $1 / 8000$ & $\begin{array}{c}123,73 \\
4\end{array}$ \\
\hline 3 & linear & $1 / 12000$ & 29 & $1 / 6000$ & 76,484 & 29 & $1 / 12000$ & $\begin{array}{c}134,48 \\
4\end{array}$ \\
\hline 4 & & $1 / 24000$ & 43 & $1 / 6000$ & 66,234 & 43 & $1 / 24000$ & $\begin{array}{c}152,23 \\
4\end{array}$ \\
\hline 5 & & 0 & 58 & $1 / 6000$ & 61,984 & 58 & 0 & $\begin{array}{c}177,98 \\
4\end{array}$ \\
\hline 6 & nonlinear & $1 / 8000$ & 15 & $1 / 6000$ & 92,797 & 15 & $1 / 8000$ & $\begin{array}{c}122,79 \\
7 \\
\end{array}$ \\
\hline 7 & $\psi \leq 1,5 \psi_{d o p}$ & $1 / 12000$ & 29 & $1 / 6000$ & 72,859 & 29 & $1 / 12000$ & $\begin{array}{c}130,85 \\
9\end{array}$ \\
\hline 8 & & $1 / 24000$ & 43 & $1 / 6000$ & 58,172 & 43 & $1 / 24000$ & $\begin{array}{c}144,17 \\
2\end{array}$ \\
\hline 9 & & 0 & 58 & $1 / 6000$ & 47,484 & 58 & 0 & $\begin{array}{c}163,48 \\
4\end{array}$ \\
\hline 10 & nonlinear & $1 / 8000$ & 22 & $1 / 6000$ & 80,109 & 22 & $1 / 8000$ & $\begin{array}{c}124,10 \\
9\end{array}$ \\
\hline 11 & $\psi \leq \psi_{d o p}$ & $1 / 12000$ & 43 & $1 / 6000$ & 50,109 & 43 & $1 / 12000$ & $\begin{array}{c}136,10 \\
9\end{array}$ \\
\hline 12 & & $1 / 24000$ & 65 & $1 / 6000$ & 26,547 & 65 & $1 / 24000$ & $\begin{array}{c}156,54 \\
7 \\
\end{array}$ \\
\hline 13 & & 0 & 86 & $1 / 6000$ & 12,484 & 86 & 0 & $\begin{array}{c}184,48 \\
4\end{array}$ \\
\hline
\end{tabular}

A total of 13 cases presented in table 1 were subjected to dynamic analysis. In accordance with the applicable regulations, the admissible values of kinematic parameters are: accelerations on a circular arc $a_{d o p}=0.6 \mathrm{~m} / \mathrm{s}^{2}$, and acceleration increments in the zone of variable curvature $\psi_{d o p}=0.5 \mathrm{~m} / \mathrm{s}^{3}$. The $l_{2}$ length results from the dependence (3) for the linear curvature and (8) for the non-linear curvature. The appropriate pattern for the linear curvature is in the form

$$
l_{2}=\frac{1}{k_{2}}\left[\theta\left(l_{1}+l_{2}+l_{3}\right)-\frac{k_{1}+k_{2}}{2} l_{1}-\frac{k_{2}+k_{3}}{2} l_{3}\right]
$$

And for the nonlinear curvature

$l_{2}=\frac{1}{k_{2}}\left[\theta\left(l_{1}+l_{2}+l_{3}\right)-\frac{3 k_{1}+5 k_{2}}{8} l_{1}-\frac{3 k_{3}+5 k_{2}}{8} l_{3}\right]$ 
Tab 2. Accelerations $a(l)\left[\mathrm{m} / \mathrm{s}^{2}\right]$ in individual zones for considered turnouts

\begin{tabular}{|c|c|c|c|}
\hline & Init & Strefa środkowa & Stref \\
\hline 1 & & $\begin{array}{l}a(l)=0,25567 \\
l \in\langle 0 ; 119,984\rangle\end{array}$ & \\
\hline 2 & $\begin{array}{l}a(l)=0,38580247+0,0085734 l \\
l \in\langle 0 ; 15,00\rangle\end{array}$ & $\begin{array}{l}a(l)=0,51440329 \\
l \in\langle 15,00 ; 108,734\rangle\end{array}$ & $\begin{array}{l}a(l)=1,446622-0,00857339 l \\
l \in\langle 108,734 ; 123,734\rangle\end{array}$ \\
\hline 3 & $\begin{array}{l}a(l)=0,25720165+0,008869 l \\
l \in\langle 0 ; 29,00\rangle\end{array}$ & $\begin{array}{l}a(l)=0,51440329 \\
l \in\langle 29,00 ; 105,484\rangle\end{array}$ & $\begin{array}{l}a(l)=1,44994324-0,008869 l \\
l \in\langle 105,484 ; 134,484\rangle\end{array}$ \\
\hline 4 & $\begin{array}{l}a(l)=0,1286008+0,008972 l \\
l \in\langle 0 ; 43,00\rangle\end{array}$ & $\begin{array}{l}a(l)=0,51440329 \\
l \in\langle 43,00 ; 109,234\rangle\end{array}$ & $\begin{array}{l}a(l)=1,49446717-0,00897215 l \\
l \in\langle 109,234 ; 152,234\rangle\end{array}$ \\
\hline 5 & $\begin{array}{l}a(l)=0,008869022 l \\
l \in\langle 0 ; 58,00\rangle\end{array}$ & $\begin{array}{l}a(l)=0,51440329 \\
l \in\langle 58,00 ; 119,984\rangle\end{array}$ & $\begin{array}{l}a(l)=1,578544061-0,00886902 l \\
l \in\langle 119,984 ; 177,984\rangle\end{array}$ \\
\hline 6 & $\begin{array}{l}a(l)=0,385802+0,012860082 l \\
-1,9052 \cdot 10^{-5} l^{3} \\
l \in\langle 0 ; 15,00\rangle\end{array}$ & $\begin{array}{l}a(l)=0,51440329 \\
l \in\langle 15,00 ; 107,797\rangle\end{array}$ & $\begin{array}{l}a(l)=-33,31296033+0,84899995 l \\
-0,00701858 l^{2}+1,9052 \cdot 10^{-5} l^{3} \\
l \in\langle 107,797 ; 122,797\rangle\end{array}$ \\
\hline 7 & $\begin{array}{l}a(l)=0,257202+0,013303533 l \\
-5,2729 \cdot 10^{-6} l^{3} \\
l \in\langle 0 ; 29,00\rangle\end{array}$ & $\begin{array}{l}a(l)=0,51440329 \\
l \in\langle 29,00 ; 101,859\rangle\end{array}$ & $\begin{array}{l}a(l)=-9,817640935+0,25757725 l \\
-0,00207002 l^{2}+5,2729 \cdot 10^{-6} l^{3} \\
l \in\langle 101,859 ; 130,859\rangle\end{array}$ \\
\hline 8 & $\begin{array}{l}a(l)=0,12860082+0,013458226 l \\
-2,42622 \cdot 10^{-6} l^{3} \\
l \in\langle 0 ; 43,00\rangle\end{array}$ & $\begin{array}{l}a(l)=0,51440329 \\
l \in\langle 43,00 ; 101,172\rangle\end{array}$ & $\begin{array}{l}a(l)=-5,20173599+0,13783265 l \\
-0,00104938 l^{2}+2,42622 \cdot 10^{-6} l^{3} \\
l \in\langle 101,172 ; 144,172\rangle\end{array}$ \\
\hline 9 & $\begin{array}{l}a(l)=0,13303533 l \\
-1,31823 \cdot 10^{-6} l^{3} \\
l \in\langle 0 ; 58,00\rangle\end{array}$ & $\begin{array}{l}a(l)=0,51440329 \\
l \in\langle 58,00 ; 105,484\rangle\end{array}$ & $\begin{array}{l}a(l)=-3,584992901+0,09239319 l \\
-0,00064653 l^{2}+1,31823 \cdot 10^{-6} l^{3} \\
l \in\langle 105,484 ; 163,484\rangle\end{array}$ \\
\hline 10 & $\begin{array}{l}a(l)=0,385802+0,008768238 l \\
-6,03873 \cdot 10^{-6} l^{3} \\
l \in\langle 0 ; 22,00\rangle\end{array}$ & $\begin{array}{l}a(l)=0,51440329 \\
l \in\langle 22,00 ; 102,109\rangle\end{array}$ & $\begin{array}{l}a(l)=-10,06995958+0,27027629 l \\
-0,00224838 l^{2}+6,03873 \cdot 10^{-6} l^{3} \\
l \in\langle 102,109 ; 124,109\rangle\end{array}$ \\
\hline 11 & $\begin{array}{l}a(l)=0,257202+0,00897215 l \\
-1,61748 \cdot 10^{-6} l^{3} \\
l \in\langle 0 ; 43,00\rangle\end{array}$ & $\begin{array}{l}a(l)=0,51440329 \\
l \in\langle 43,00 ; 93,109\rangle\end{array}$ & $\begin{array}{l}a(l)=-2,60009332+0,08092239 l \\
-0,00066046 l^{2}+1,61748 \cdot 10^{-6} l^{3} \\
l \in\langle 93,109 ; 136,109\rangle\end{array}$ \\
\hline 12 & $\begin{array}{l}a(l)=0,12860082+0,008903134 l \\
-7,02417 \cdot 10^{-7} l^{3} \\
l \in\langle 0 ; 65,00\rangle\end{array}$ & $\begin{array}{l}a(l)=0,51440329 \\
l \in\langle 65,00 ; 91,547\rangle\end{array}$ & $\begin{array}{l}a(l)=-1,172456697+0,04273918 l \\
-0,00032988 l^{2}+7,02417 \cdot 10^{-7} l^{3} \\
l \in\langle 91,547 ; 156,547\rangle\end{array}$ \\
\hline 13 & $\begin{array}{l}a(l)=0,0897215 \\
-4,04369 \cdot 10^{-7} l^{3} \\
l \in\langle 0 ; 86,00\rangle\end{array}$ & $\begin{array}{l}a(l)=0,51440329 \\
l \in\langle 86,00 ; 98,484\rangle\end{array}$ & $\begin{array}{l}a(l)=-0,883733908+0,0323152 l \\
-0,0002238 l^{2}+4,04369 \cdot 10^{-7} l^{3} \\
l \in\langle 98,484 ; 184,484\rangle\end{array}$ \\
\hline
\end{tabular}


On a circular arc without transition curves (case 1 from Table 1), the change in acceleration takes place linearly on the length of the $l_{b}$ wagon rigid base. In the initial (and final) zone containing the linear curvature (cases $2 \div 5$ ), the $\psi$ value is constant over the length. In the case of non-linear (polynomial) curvature, the value is variable in length. For cases $6 \div 9$, there is a condition:

$\psi_{\max }=\max \left[\left(\frac{V}{3,6}\right)^{3}\left(\frac{1}{R_{2}}-\frac{1}{R_{1}}\right) \frac{3}{2 l_{1}}-\left(\frac{V}{3,6}\right)^{3}\left(\frac{1}{R_{2}}-\frac{1}{R_{1}}\right) \frac{3}{2 l_{1}^{3}} l^{2}\right] \leq 1,5 \psi_{\text {dop }}$

The $50 \%$ increase in the normative admissible value $\psi_{d o p}$ results from the fact that the $\psi_{\max }$ value occurs only at one point (for $l=0$ ), and then decreases, reaching the zero point at the end of the segment (for $l=l_{1}$ ). However, if we want to keep the $\psi_{\text {dop }}$ value for the non-linear curvature segments, then we must increase the $l_{1}$ length by $50 \%$. Such a situation is considered in cases $10 \div 13$.

The purpose of introducing the dynamic criterion was to perform a comparative analysis of different geometrical systems of the turnout diverging track in terms of the impact of their shape on the size of the transverse interactions occurring in the track-rail vehicle system. The basic problem of using complex mathematical models in modeling the dynamics of such a system is the interpretation of the obtained results, especially in relation to the track. In the works $[1,7,12]$ there are extensive models of rail vehicles, striving to faithfully reflect reality used. Complex forms of motion equations require the determination of experimental parameters of specific vehicle types: masses and moments of inertia, elastic characteristics, damping characteristics. In work [12], the object of analysis is a two-axle wagon and two types of trolleys with 18 or 16 degrees of laxity. The model describes the vertical and horizontal flexibility of the track, assuming constant stiffness and damping parameters. In the paper [7], a model of a rail vehicle with 46 degrees of laxity and a surface model with 1 degree of laxity (displacements in the transverse direction to the track axis) were used to analyze the passenger's comfort, which made the vehicle features clearly dominate over the influence of the geometric shape of the track. Therefore, the design aspects of the rail vehicle itself have been omitted in this work [8].

To evaluate the dynamic impacts, a simplified model of a rail vehicle was adopted, which passed the exam in earlier works devoted to the analysis of the impact of the geometric layout of the track on the magnitude of impact $[2,4,6]$. The dynamic model used takes into account the length of the wagon rigid base (in this case $l_{b}=20 \mathrm{~m}$ ). This results in some relaxation of the acceleration $a(l)$, forcing transverse vibrations, which are reduced to $a_{k o r}(l)$ values. The list of analyzed accelerations for the considered cases is included in the table 2.

The solution to the problem is the $X(t)$ function, which shows the deviation of the vehicle in the transverse direction under the influence of $P(t)=m \cdot a(t)$ force. The $X(t)$ function is a resultant of the static component and vibrations of the system. From the point of view of the assessment of dynamics, it is important to consider the accelerations in the vibrating motion $a_{v}=\ddot{X}(t)$. The highest amplitude of accelerations in the oscillating motion $|\max \ddot{X}|$ and the modified index were used as the assessment criteria

$$
w_{a}=\int_{l_{0}}^{l_{0}+l_{k}}|\ddot{X}(t)| d l
$$

where: $l_{0}$ - the point of entry of the rail vehicle trolley on the characteristic point,

$l_{k}$ - the length of the taken section needed to damp vibrations. 


\section{The results of the analysis}

Table 3 presents the calculated values of the $w_{a}$ indicator and the highest amplitude $\max \ddot{X}$ for all considered cases. The obtained diagrams of vibration acceleration $\ddot{X}(l)$ for selected cases with sections of linear curvature are shown in the figures $\mathbf{3}$ and $\mathbf{4}$.

Tab 3. Compilation of calculated indicator values $w_{a}$ and the highest amplitude $\max \ddot{X}$

\begin{tabular}{|c|c|c|c|c|c|c|c|c|}
\hline \multirow{3}{*}{ Case } & \multicolumn{8}{|c|}{ Area of impacts } \\
\hline & \multicolumn{2}{|l|}{$k_{1}$} & \multicolumn{2}{|l|}{$k_{1}-k_{2}$} & \multicolumn{2}{|l|}{$k_{2}-k_{3}$} & \multicolumn{2}{|l|}{$k_{3}$} \\
\hline & $\begin{array}{l}w_{a} \\
{\left[\mathrm{~m}^{2} / \mathrm{s}^{2}\right]}\end{array}$ & $\begin{array}{l}|\max \ddot{X}| \\
{\left[\mathrm{m} / \mathrm{s}^{2}\right]}\end{array}$ & $\begin{array}{l}w_{a} \\
{\left[\mathrm{~m}^{2} / \mathrm{s}^{2}\right]}\end{array}$ & $\begin{array}{l}|\max \ddot{X}| \\
{\left[\mathrm{m} / \mathrm{s}^{2}\right]}\end{array}$ & $\begin{array}{l}w_{a} \\
{\left[\mathrm{~m}^{2} / \mathrm{s}^{2}\right]}\end{array}$ & $\begin{array}{l}|\max \ddot{X}| \\
{\left[\mathrm{m} / \mathrm{s}^{2}\right]}\end{array}$ & $\begin{array}{l}w_{a} \\
{\left[\mathrm{~m}^{2} / \mathrm{s}^{2}\right]}\end{array}$ & $\begin{array}{l}|| \max \ddot{X} \mid \\
{\left[\mathrm{m} / \mathrm{s}^{2}\right]}\end{array}$ \\
\hline 1 & 216,9 & 174,4 & 0 & 0 & 0 & 0 & 216,9 & 174,4 \\
\hline 2 & 659,9 & 531,8 & 4,44 & 3,12 & 4,37 & 3,38 & 660,8 & 526,4 \\
\hline 3 & 440,3 & 355,4 & 4,02 & 3,23 & 3,9 & 2,9 & 439,5 & 351,6 \\
\hline 4 & 178,9 & 220,6 & 3,27 & 4,21 & 3,13 & 4,06 & 174,5 & 219,1 \\
\hline 5 & 4,22 & 3,23 & 4,21 & 3,23 & 4,25 & 3,29 & 4,28 & 3,29 \\
\hline 6 & 660,7 & 533,02 & 0,46 & 0,26 & 0,17 & 0,16 & 653,6 & 522,35 \\
\hline 7 & 440,8 & 356,64 & 0,15 & 0,06 & 0,22 & 0,04 & 434,6 & 346,84 \\
\hline 8 & 221,2 & 180,19 & 0,18 & 0,04 & 0,56 & 0,48 & 199,2 & 157,50 \\
\hline 9 & 6,38 & 4,85 & 0,08 & 0,03 & 0,08 & 0,03 & 7,67 & 5,86 \\
\hline 10 & 659,9 & 531,9 & 0,02 & 0,05 & 0,16 & 0,09 & 647,5 & 523,7 \\
\hline 11 & 440,3 & 355,5 & 0,07 & 0,03 & 0,07 & 0,03 & 436,7 & 349,4 \\
\hline 12 & 220,7 & 178,9 & 0,06 & 0,02 & 0,09 & 0,04 & 214,77 & 171,1 \\
\hline 13 & 4,28 & 3,27 & 0,05 & 0,008 & 0,05 & 0,008 & 5,08 & 3,93 \\
\hline
\end{tabular}




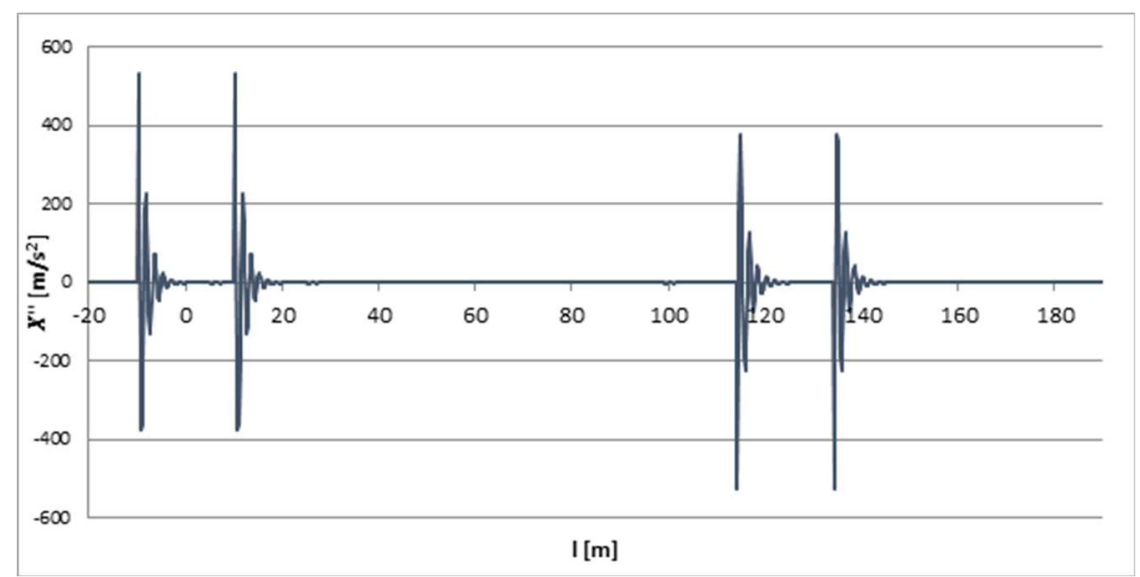

3. Graphs of vibrating motion acceleration $\ddot{X}(l)$ for case No. 2 (sections of linear curvature, $k_{1}=k_{3}=1 / 8000 \mathrm{rad} / \mathrm{m}$ )

From Table 3, graphs of acceleration of vibrating motion in Figures $\mathbf{3}$ and $\mathbf{4}$ clearly show that in the case of using linear curvature sections, the extreme curvature $k_{1}$ and $k_{3}$ play a decisive role. With the decrease of these values the amplitudes of vibrations in the initial and final regions decrease $k_{1}=k_{3}=0$, so that very small values can be assumed (Fig. 4). Similar values as in this case also occur in the initial and final region of a circular arc and - as shown in Table $\mathbf{3}$ - this applies to all considered cases.

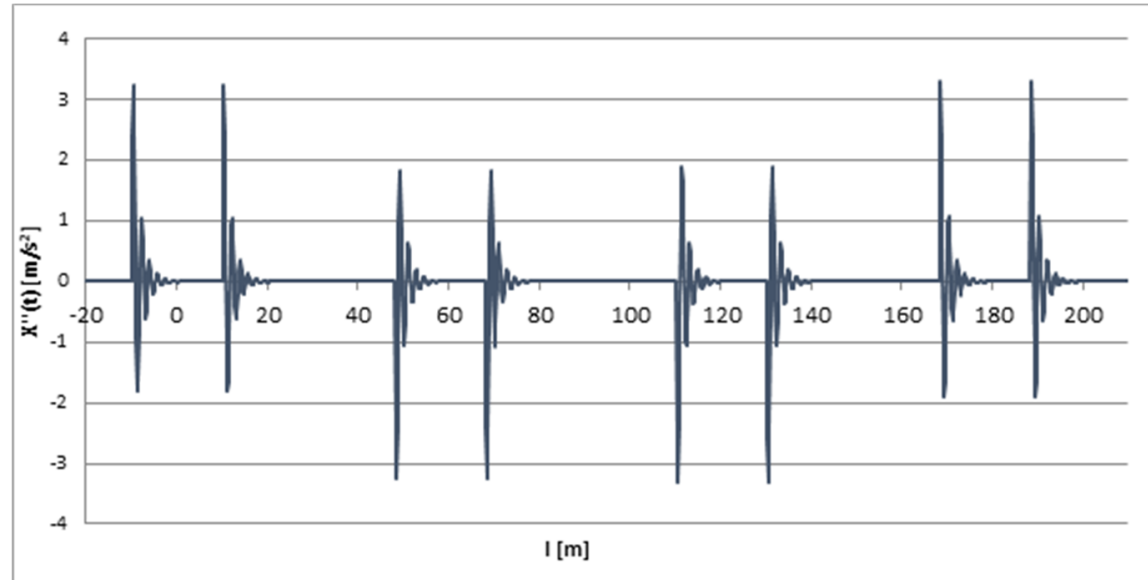

4. Graphs of vibrating motion acceleration $\ddot{X}(l)$ for the case No. 5 (sections of linear curvature, $k_{1}=k_{3}=0$ )

In the case of using non-linear curves, the graphs of acceleration of the oscillating motion in the extreme regions of the turnout diverging track have a similar course to the diagrams shown in Figures 3 and 4. A significant difference, however, appears in the initial and ending regions of the circular arc (Figure $\mathbf{5}$ and Table $\mathbf{3}$ ). 


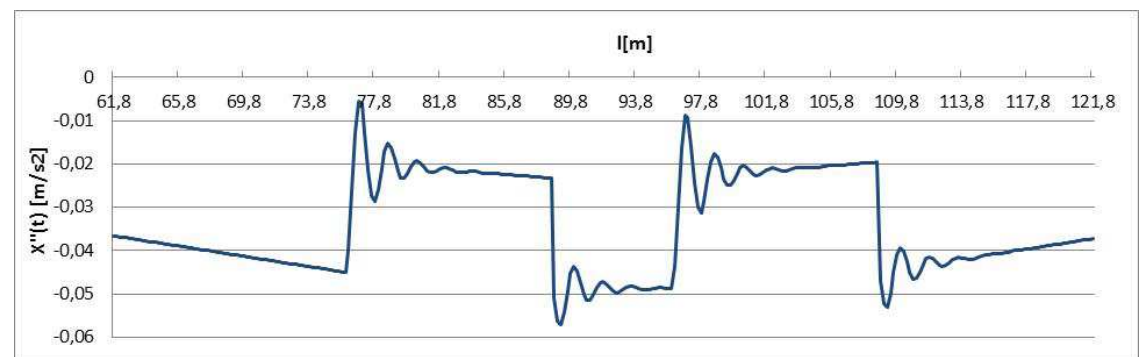

5. Graphs of vibrating motion acceleration $\ddot{X}(l)$ in the middle zone for the case No.13 (sections of non-linear curvature, $k_{1}=k_{3}=0$ )

As you can see, the use of non-linear curves in practice reduces to zero the dynamic effects in the central zone and this applies to all accepted values $k_{1}$ and $k_{3}$. Definitely the most favorable situation occurs when $k_{1}=k_{3}=0$ in the extreme zones the acceleration of the vibrating motion is the smallest. However, in order to obtain similar values as for linear segments, the same value of acceleration gain should be kept $\psi_{\text {dop }}$ (cases $10 \div 13$ ). This means that it is necessary to increase the length of the nonlinear curvature segments by $50 \%$ compared to linear sections.

Considering all the conditions, case No.13 is definitely the best solution, with sections of nonlinear curvature, zero curvature at the start and the end of the turnout, and maintaining the valid admissible value of acceleration gain. Figure $\mathbf{6}$ shows a graph of curvature along the turnout diverging track for this case.

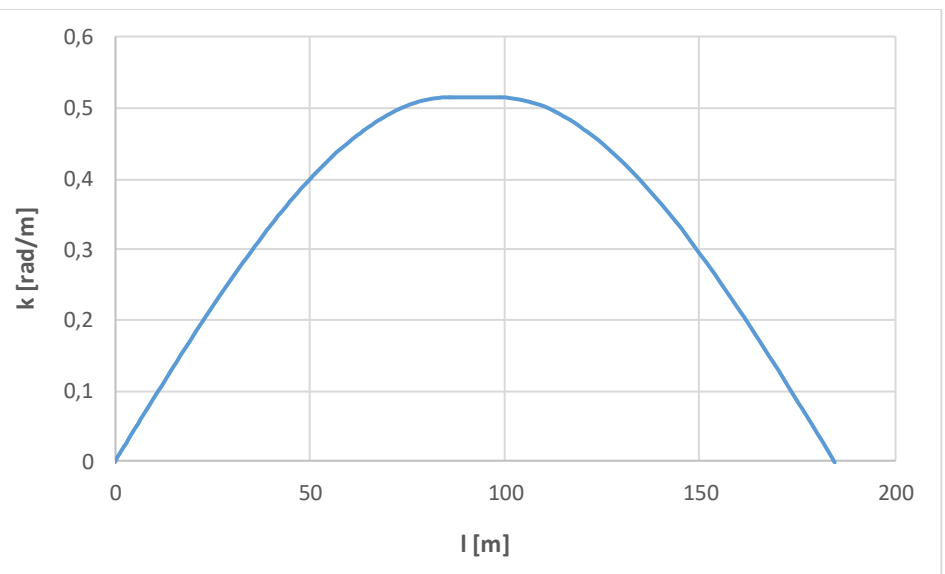

6. Diagram of curvature with nonlinear sections along the turnout diverging track

$$
\left(k_{1}=0, l_{1}=86 \mathrm{~m}, k_{2}=1 / 6000 \mathrm{rad} / \mathrm{m}, l_{2}=12,484 \mathrm{~m}, l_{3}=86 \mathrm{~m}, k_{3}=0\right)
$$

\section{Summary}

In the diverging track of a typical railway turnout (ordinary), a single circular arc is used without transients. As a result, there are places of rapid, abrupt change in the ordinates of the curvature diagram at the start and end of the turnout. In recent years, in some countries, especially on high-speed railways, the aim is to smooth out the curvature diagram in these regions, introducing the so-called "clothoid sections" on both sides of a circular arc on which the curvature varies in a linear manner.

This work presents an analytical method of solving the problem, which is general and full. Appropriate equations have been determined for both the occurrence of linear curvature segments as well as for the proposed non-linear sections (in polynomial form). The given theoretical relations include- separately-both basic variants of the curvature distribution 
(linear and nonlinear) and are of universal nature, among others allow you to accept any curvature values at the beginning and at the end of the geometric layout.

Carefully selected geometrical cases were subjected to a comparative analysis in terms of determining the impact of their shape on the size of the transverse interactions occurring in the track - rail vehicle system, using the appropriate dynamic model. To evaluate the dynamic impacts, a simplified model of a rail vehicle with one degree of laxity was adopted, consisting of mass, spring, and silencer, and considering the length of the rigid wagon base that passed the exam in previous works devoted to the analysis of the impact of the track geometric system on the impact.

As a result of the dynamic analysis, it has been shown that the most advantageous properties have a turnout diverging track with nonlinear curvature in the initial zone and end zone and zero curvature values at the endpoints of the geometrical layout, with appropriate elongation of nonlinear curvature sections compared to linear sections for the same value permissible acceleration gain. At the same time, there was a doubt as to whether it has its justification in the executive practice to use the so-called "clothoid sections" with non-zero curvature values at the starting and ending points of the diverging track.

\section{Source materials}

[1] Chudzikiewicz A., Droździel J., Kisilowski J., Żochowski A. Modelowanie i analiza dynamiki układu mechanicznego tor - pojazd. Warszawa: PWN 1982.

[2] Koc W.: Analiza dynamiczna wydłużania krzywych przejściowych przy odchyleniu stycznej do łuku. Zesz. Nauk. Pol. Gdańskiej 1991, nr 459, seria Budownictwo Lądowe XLVI, s. 77-103.

[3] Koc W. Analytical method of modelling the geometric system of communication route. Mathematical Problems in Engineering, 2014, Article ID 679817.

[4] Koc W.: Krzywe przejściowe z nieliniowymi rampami przechyłkowymi w warunkach eksploatacyjnych PKP. Zesz. Nauk. Pol. Gdańskiej, 1990, nr 462, seria Budownictwo Lądowe XLVII, s. 3-129.

[5] Koc W., Palikowska K. Dynamic analysis of the turnout diverging track for HSR with variable curvature sections. World Journal of Engineering and Technology, 2017, vol. 5, pp. 42-57.

[6] Koc W., Palikowska K. Intelligent modelling of the railway track layouts using dynamic criteria. International Conference of Modelling and Management in Transportation, Poznań - Kraków 1999, vol.1, pp. 245-250.

[7] Kufver B. Optimization of clothoid lengths - simulations of dynamic vehicle reactions on horizontal curves with track irregularities. Conference Papers of The Third International Conference RAILWAY ENGINEERING 2000, London, UK.

[8] Marczewski R., Podemski J. Wagony kolejowe. Odsprężynowanie. Warszawa: WKŁ 1978.

[9] Parsons Brinckerhoff for the California High-Speed Rail Authority. Technical Memorandum: Alignment design standards for high-speed train operation, 2009.

[10] Ping W. Design of High-Speed Railway Turnouts. Theory and Applications. Elsevier Science \& Technology, Oxford, United Kingdom, 2015.

[11] Weizhu F. Major technical characteristics of High-Speed turnout in France. Journal of Railway Engineering Society, 2009, no. 9, pp. 18-35.

[12] Zboiński K. Numerical studies on railway vehicle response to transition curves with regard to their different shape. Archives of Civil Engineering, 1998, vol. XLIV, iss. 2, pp. 151-181. 